DOI: http://dx.doi.org/10.5007/1980-3532.2015n13p30

\title{
Fragmentos de Sociologia pré-acadêmica no ensino normalista de 1935
}

\author{
Fragments of Pre-academic sociology in normal \\ education in 1935
}

\author{
Cristiano das Neves Bodart \\ Doutor em Sociologia pela Universidade de São Paulo/USP \\ Docente da Faculdade Novo Milênio \\ cristianobodart@hotmail.com
}

\begin{abstract}
Resumo: Neste artigo são analisados e discutidos conteúdos abordados no âmbito do ensino de Sociologia no contexto em uma escola normalista rural da década de 1930. Tal discussão corrobora no sentido de desvendar aspectos e disputas ideológicas que envolveram o ensino de Sociologia nesse período de inclusão obrigatória no ensino brasileiro. Para tal empreitada adotamos a análise documental, mais especificadamente de provas escolares aplicadas em 10 de agosto de 1935 na Escola Normal Municipal de Alegre, que localizava-se no interior do Espírito Santo. Identificamos que há, no ensino de Sociologia, elementos que indicam que nesse período sua prática esteve marcada pela presença de fundamentos religiosos e que a "Sociologia pré-acadêmica" convergia-se no ensino de uma "Sociologia pré-científica" ou "Cristã".
\end{abstract}

Palavras-Chave: Ensino de Sociologia. Sociologia pré-acadêmica. Sociologia pré-científica. Sociologia Católica.

\begin{abstract}
In this article, content approached at the level of the teaching of Sociology in the context of a rural teacher training school in the decade of the 30s is analyzed and discussed. This discussion contributes in the sense of uncovering aspects and ideological disputes involved in the teaching of Sociology in this period of mandatory inclusion in Brazilian education. For such an undertaking, we made use of documental analysis, more specifically, of school tests taken on August 10, 1935, at the Municipal Normal School of Alegre, located in the interior of the state of Espirito Santo. We identified that there are, in the teaching of Sociology, elements which indicate that in this period, its practice was marked by the presence of religious bases, and that "pre-academic Sociology" converged in the teaching of a "pre-scientific," or "Christian," Sociology.
\end{abstract}

Keywords: Teaching Sociology, Pre-academic Sociology, Pre-scientific Sociology, Catholic Sociology.

Originais recebidos em: 08/03/2016

Aceito para publicação em: 13/05/2016

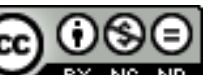

Uso Não-Comercial-Vedada a criação de obras derivadas 3.0 Unported License.

Revista Em Debate (UFSC), Florianópolis, volume 13, p. 30-51, 2015. ISSNe 1980-3532 


\section{INTRODUÇÃO E BREVE CONTEXTUALIZAÇÃO HISTÓRICA}

A História do Ensino de Sociologia no Brasil vem despertando o interesse de diversos pesquisados preocupados com o ensino de tal disciplina, o que pode ser observado a partir da presença da temática no "IV Encontro Nacional de Ensino de Sociologia na Educação Básica" e o lançamento de um dossiê na Revista Café com Sociologia ${ }^{1}$, além do crescente número de pesquisas recentes.

Em 2010, Ileizi Luciana Fiorelli Silva, pesquisadora reconhecida no campo Ensino de Sociologia, corroborou com uma coletânea destinada ao fortalecimento do ensino de Sociologia; nele levantou uma questão que é o pontapé inicial do presente artigo. Assim ponderou Silva:

\footnotetext{
Onde, quando e como foi efetivamente ensinada a Sociologia no Brasil? Há uma necessidade de buscar fontes, documentos, criar dados primários sobre as práticas de ensino de Sociologia nas Escolas Normais, nas Escolas Secundárias, no Secundo Grau, entre outros (SILVA, 2010, p. 22. Grifo nosso).
}

Este artigo busca justamente corroborar para o conhecimento e análise de fontes primárias que desvelam as dúvidas em torno das práticas cotidianas de ensino de Sociologia no Brasil da primeira metade do século XX. Para tanto, tomamos como objeto de análise dez (10) provas discursivas de Sociologia aplicadas na antiga Escola Normal Municipal de Alegre, em 10 de agosto de 1935. A análise dar-se-á sobre as questões abordadas na avaliação, as respostas dos educandos e a aferição do julgamento do professor. As provas foram encontradas no Acervo Público do Estado Espírito Santo e organizadas na caixa $n^{\circ} 150$ do Fundo Estadual de Educação, a qual encontra-se disponível para consultas públicas.

Não é pretensão narrar toda a história do ensino de Sociologia; porém algumas contextualizações são necessárias para entendermos o contexto de elaboração e aplicação das avaliações analisadas, bem como a compreensão do que seriam respostas consideradas corretas na época.

Podemos aferir que a primeira fase do ensino de Sociologia no Brasil tem início em 1882 com a proposta de Rui Barbosa, ano que se incluiu "Elementos de Sociologia e Direito Constitucional" nas escolas secundárias e nas faculdade de Direito (SILVA,

\footnotetext{
${ }^{1} \mathrm{O}$ dossiê foi publicado no volume 4, número 3 da Revista Café com Sociologia, estando disponível em: < http://revistacafecomsociologia.com/revista/index.php/revista/issue/view/14/showToc >. Acesso em: 20 abr. 2016.
}

Revista Em Debate (UFSC), Florianópolis, volume 13, p. 30-51, 2015. ISSNe 1980-3532 
2010; MORAES, 2011). Em 1891 a Reforma Benjamin Constant propõe, de forma oficial, a inclusão da Sociologia como disciplina do ensino secundário, o que acaba não se efetivando e a proposta retirada em 1901, com a Reforma Epitácio Pessoa (SILVA, 2010). Em 1925 a Sociologia foi oficialmente incluída no currículo obrigatório e ratificada em 1931 com a Reforma Francisco Campos. Em 1942, no entanto, a Reforma Capanema retirou sua obrigatoriedade no ensino secundário.

Por questões didáticas optamos em pensar a trajetória do ensino de Sociologia a partir de uma periodização, ainda que corremos o risco de simplificar a história dessa disciplina. Reconhecemos, como destacou Moraes (2011, p. 360), que

\footnotetext{
As cronologias encerram certo paradoxo. Apresentam-se fundamentadas numa objetividade de datas que, no entanto, estão marcadas pela escolha que o autor da cronologia exerce e, mais do que isso, ou por isso, tal escolha já é índice de interpretação, ou seja, está sujeita a uma subjetividade.
}

Adotamos aqui a cronologia destacada por Silva (2010) a qual fundou-se nos principais estudos em torno do ensino de Sociologia no Brasil. De acordo com Silva, a primeira fase vai de 1880 a 1930, a segunda de 1931 a 1941 e uma terceira fase delimitada entre 1942 a 1964. Nos interessa as duas primeiras fases por nosso objeto de estudo está situado no ano de 1935.

A primeira fase tem início em 1882 com a proposta de Rui Barbosa de incluir "Elementos de Sociologia e Direito Constitucional" nas escolas secundárias e instituir, nas faculdades de Direito, a Sociologia no lugar da disciplina Direito Natural (SILVA, 2010; MORAES, 2011). A proposta inicial de inclusão dessas disciplinas estava marcada por uma expectativa cívica-redentora (MORAES, 2011). Essa proposta não chegou a ter andamento no parlamento, não sendo nem mesmo lida. Contudo, sua importância deu-se pela abertura de uma reflexão marcada pelo princípio positivista e o desenvolvimento de escritas sociológicas por parte de alguns intelectuais brasileiros que buscavam pensar a realidade social do país (CIGALES, 2014). Em 1890, Benjamim Constant, então Ministro da Guerra, introduziu o ensino de "Sociologia e Moral" nas escolas do Exército. Como Ministro da Instrução Pública, tentou incluir a Sociologia em todo os níveis e modalidades de ensino, contudo, sem êxito (SILVA, 2010). De acordo com Oliveira (2013, p. 180), a proposta de Reforma de Benjamin Constant previa uma Educação Básica de sete anos, e no segundo semestre do último ano os alunos teriam acesso a disciplina 'Sociologia e Moral'. Já nas Escolas Normais, segundo Oliveira (2013), no último ano do curso o aluno estudaria Sociologia 
separadamente da disciplina 'Moral', sendo elementos curriculares distintos. "Essa primeira fase é caracteriza-se pela busca da cientificização das explicações sobre a natureza e a sociedade", estando o pensamento social sobre forte influência do iluminismo, positivismo e evolucionismo e a presença de vários especialistas autodidatas e a implantação do ensino de Sociologia em cursos não especializados, tais como nos cursos de Direito e de formação de militares, assim como em escolas secundárias (SILVA, 2010, p. 19). Havia nessa fase uma "disputa entre as explicações católicas e jurídicas versus as explicações positivistas, evolucionistas e cientificistas", embate que perdurará por décadas e aparecerão nos manuais de Sociologia que proliferaram a partir de 1925 (SILVA, 2010, p. 20).

A segunda fase, delimitada entre 1931 a 1941, é marcada por "elementos do processo de configuração do ensino de Sociologia na Escolas Secundária e no Ensino Superior" (SILVA, 2010, p. 21). Nesse período temos a presença obrigatória da Sociologia no ensino secundário, a proliferação de manuais de Sociologia e a criação dos primeiros cursos superiores de Ciências Sociais no Brasil.

Pontuando de forma cronológica, para efeitos didáticos, tivemos, no ano de 1925 a Reforma Rocha Vaz (Decreto n. 16.782-A, de 13/01/1925) tornando obrigatória a Sociologia nos anos finais dos cursos preparatórios, embora sua efetividade estivesse limitada pela autonomia dos Estados; em 1929 dar-se a introdução da cadeira de Sociologia nas escolas normais de Pernambuco e do Rio de Janeiro (1928); em 1931 ocorreu a Reforma Francisco Campos (Decreto n. 19.890, de 18 de abril de 1931) mantendo a Sociologia nos anos finais do ensino secundário; em 1933 foi criado a Escola Livre de Sociologia e Política de São Paulo, ofertando o curso superior de Sociologia destinado à qualificação técnica de funcionários da administração pública e privada; em 1934 foi fundada a Universidade de São Paulo, tendo o catedrático de Sociologia, Fernando de Azevedo, como diretor da Faculdade de Filosofia, Ciências e Letras e; em 1935 a Sociologia torna-se disciplina no curso normal do Instituto Estadual de Educação de Florianópolis; ainda em 1935 outro curso de Ciências Sociais foi criado, este na Universidade do Distrito Federal (SILVA, 2010; MORAES, 2011; CIGALES, 2014). Essa segunda fase encerrou-se com a retirada da obrigatoriedade da Sociologia nos cursos secundários na reforma educacional de 1942, conhecida como Reforma Capanema. No entanto, a Sociologia manteve-se presente no curso normal, geralmente na especificidade de Sociologia da Educação.

A terceira fase é marcada pela inflexão da Sociologia no ensino secundário e Revista Em Debate (UFSC), Florianópolis, volume 13, p. 30-51, 2015. ISSNe 1980-3532 
pelo continuo desenvolvimento da Sociologia nos espaços de pesquisas e universidades (SILVA, 2010).

Quando se busca elucidar a configuração das Ciências Sociais/Sociologia no Brasil partindo da sua produção científica, não é possível encontrar, até 1933, espaços oficiais de formação e produção acadêmica e por isso convencionou-se denominar esse período de fase pré-acadêmica. Nesta fase comumente praticava-se as Ciências Sociais de forma autodidata, sendo o ensino de Sociologia, nos cursos de preparação para o exercício do magistério, nas escolas normais, e nas então denominadas Escolas Secundárias ministrado por professores sem formação específica (SILVA, 2010, p. 16). Contudo, haviam alguns poucos professores que se formavam na Europa, tais como Delgado de Carvalho e Adrien Delpech que lecionavam no colégio Pedro II.

A institucionalização acadêmica da Sociologia no Brasil ocorreu, sobretudo, com a criação da Escola Livre de Sociologia e Política de São Paulo (1933) e com a criação da Seção de Sociologia e Ciência Política da Faculdade de Filosofia da Universidade de São Paulo (1934). Esses dois acontecimentos demarcam o início da chamada Sociologia Científica no Brasil, "a qual viria a ter seu apogeu em fins dos anos de 1950” (LIEDKE FILHO, 2005). Embora até 1935 já havia tido início alguns cursos de Sociologia no Brasil, a formação esteve voltada prioritariamente para a pesquisa e a qualificação de Administradores públicos e privados, o que nos indica que o seu impacto sobre o ensino de uma Sociologia Cientificista não teria sido de imediato, sobretudo em escolas interioranas, tais como a Escola Normal Municipal de Alegre.

O processo de institucionalização das Ciências Sociais no Brasil, e em particular, do ensino de Sociologia, teve o ensino secundário como ponto de partida, antes mesmo de conquistar espaço na academia (MEUCCI, 2000). Diferentemente das muitas experiências nos países hispano-americano, onde, em geral, o ensino de Sociologia teve início nas faculdade de Direito, no Brasil a Sociologia teve início no final do século XIX, no Atheneu Sergipense (OLIVEIRA, 2013) e, posteriormente, no Colégio Pedro II (1925) e nas escolas normais equiparadas a este (AZEVEDO, 1973, p. 320).

A presença da Sociologia no Brasil após 1925 foi entendida [...] como uma área de conhecimento dedicada à renovação da vida intelectual, à substituição do ensaísmo jurídico e literário pelo realismo científico (MEUCCI, 2011, p. 57).

De acordo com Meucci (2011), a permanência da Sociologia no ensino secundário entre 1925 a 1942 e um mercado editorial favorável ao investimento na área pedagógica, fizeram com que, a partir dos anos de 1930, houvesse uma explosão de Revista Em Debate (UFSC), Florianópolis, volume 13, p. 30-51, 2015. ISSNe 1980-3532 
manuais de Sociologia. Essa mesma autora realizou um levantamento dos manuais que circularam nas escolas do país, tendo identificado, entre os anos de 1931 e 1945, 35 títulos. Dentre esses títulos estavam autores ilustres, tais como Delgado de Carvalho, Fernando de Azevedo, Gilberto Freyre e Amaral Fontoura.

Os livros didáticos são, quase sempre, os norteadores da prática docente e estes estão marcados por "projetos educacionais" próprios. Nos anos de 1930 identificamos uma disputa pelo "projeto educacional" entre uma "Sociologia Cientificista" e uma "Sociologia Cristão ou Católica" (MEUCCI, 2011; CIGALES, 2015). A Sociologia Cristão, ou Católica, parecia ser uma reação às transformações da sociedade e aos riscos que parceria impor ao ideário católico (DAROS; PEREIRA, 2015) e os livros didáticos configuraram-se em veículos de expressão de interesses políticos e ideológicos em torno do "projeto de educação" (MEUCCI, 2011). Fernandes (1980) destacou que a Sociologia no Brasil estava bastante atrelada à europeia, sendo absorvida pelos intelectuais como "novidades" intelectuais. Os primeiros professores dos cursos superiores de Ciências Sociais eram europeus, sobretudo franceses, deixando profundas influências sobre as interpretações sociológicas do Brasil.

A Sociologia brasileira da primeira metade do século XX estava marcada por disputas ideológicas que tinha, de um lado, a "Sociologia Cientificista" e, por outro, a Sociologia Cristã. Os intelectuais católicos como Theobaldo Miranda Santos e Alceu Amoroso Lima atuaram de forma marcante na defesa de uma Sociologia espiritualista ou cristã a embasar a formação docente (DAROS; PEREIRA, 2015). Essa disputa esteve presente no âmbito da Associação Brasileira de Educação (ABE), que entre 1929 e 1932, esteve sob forte controle dos católicos, fato que se modificou apenas a partir da IV Conferência Nacional de Educação, promovida por esse mesmo órgão em 1932, momento que foi apresentado o Manifesto dos Pioneiros da Escola Nova, o qual não contemplou os interesses dos intelectuais católicos (DAROS; PEREIRA, 2015).

Para compreendermos como se configurava o ensino de Sociologia é importante a análise de manuais, do currículo, da formação dos professores, como também das práticas pedagógicas. Estas nos desvelam as dúvidas em torno das práticas cotidianas, corroborando para a compreensão dos embates ideológicos existentes na sala de aula. Como as provas discursivas analisadas são do ano de 1935, busca-se identificar se já há predominância de uma "Sociologia cientificista" ou ainda encontramos uma prática de ensino fortemente marcada por "fragmentos de uma Sociologia pré-acadêmica" ou a presença de uma Sociologia Cristã. Chamamos aqui de "fragmentos", elementos 
fracionários do cotidiano (no caso desse artigo, as provas escolares), os quais não são capazes de fornecer condições para elucidarmos todo um contexto no qual estão inseridos, mas nos servem de ponto de partida para a maior compreensão das configurações do ensino de Sociologia no Brasil.

O presente artigo está dividido em três seções. A primeira é a presente introdução e contextualização histórica do ensino de Sociologia no Brasil. Na segunda seção realizamos uma apresentação, caracterização do objeto e algumas reflexões em torno das avaliações escolares. Por fim, na terceira seção, apresentamos algumas considerações finais.

\section{FRAGMENTOS DO ENSINO DE SOCIOLOGIA: O QUE AS PROVAS ESCOLARES DA ESCOLA NORMAL MUNICIPAL DE ALEGRE PODEM NOS INDICAR?}

O que chamamos aqui de "fragmentos do ensino de Sociologia" são dez (10) provas de Sociologia que foram aplicadas na antiga Escola Normal Municipal de Alegre, em 10 de agosto de 1935 a alunos do quatro $\left(4^{\circ}\right)$ anos do curso normal. Ao todo são 42 páginas de provas encontradas. Tais provas, como já mencionado, foram encontradas no Acervo Público do Estado Espírito Santo. A julgar pelos nomes, todos os alunos eram do sexo feminino. As provas são identificadas pela Escola por um número correspondente ao aluno. Notamos que os números vão até 12, porém apenas 10 provas foram encontradas. Não sabemos se duas se perderam ou corresponde à alunos que deixaram de fazer a avaliação ou evadiram-se do curso.

A Escola Normal Municipal de Alegre, como seu nome indicava, ofertava o ensino de curso normal e estava localizada no município de Alegre, no sul do estado do Espírito Santo. O município de Alegre foi criado em 03 de abril de 1884, sendo oficialmente instalados a vila e o município em 06 de janeiro de 1891, sendo na ocasião desmembrada do município de Cachoeiro de Itapemirim. Ambos os municípios tinham tradição agrária, marcada pela presença de diversas famílias abastadas e forte presença da Igreja Católica e uma sociedade cristã conservadora.

Há poucas informações sobre a Escola Normal Municipal de Alegre. Fundada como uma escola normalista, em 05 de outubro de 1933 deu-se o pedido de 
equiparação ${ }^{2}$ oficial ao Colégio Pedro II, pedido apresentado em solenidade em 12 de novembro de 1933 (DIÁRIO DA MANHÃ, 12/11/1933). Nesse mesmo ano, no mês de dezembro, a escola realizou a primeira formatura (DIÁRIO DA MANHÃ, 20/12/1933). A equiparação acorreu oficialmente no dia seguinte, por meio do Decreto ${ }^{\circ} 3.416$ de 21 de dezembro de $1933^{3}$. Atualmente no prédio onde sediava a escola normal funciona a Escola Estadual de Ensino Fundamental e Médio Aristeu Aguiar.

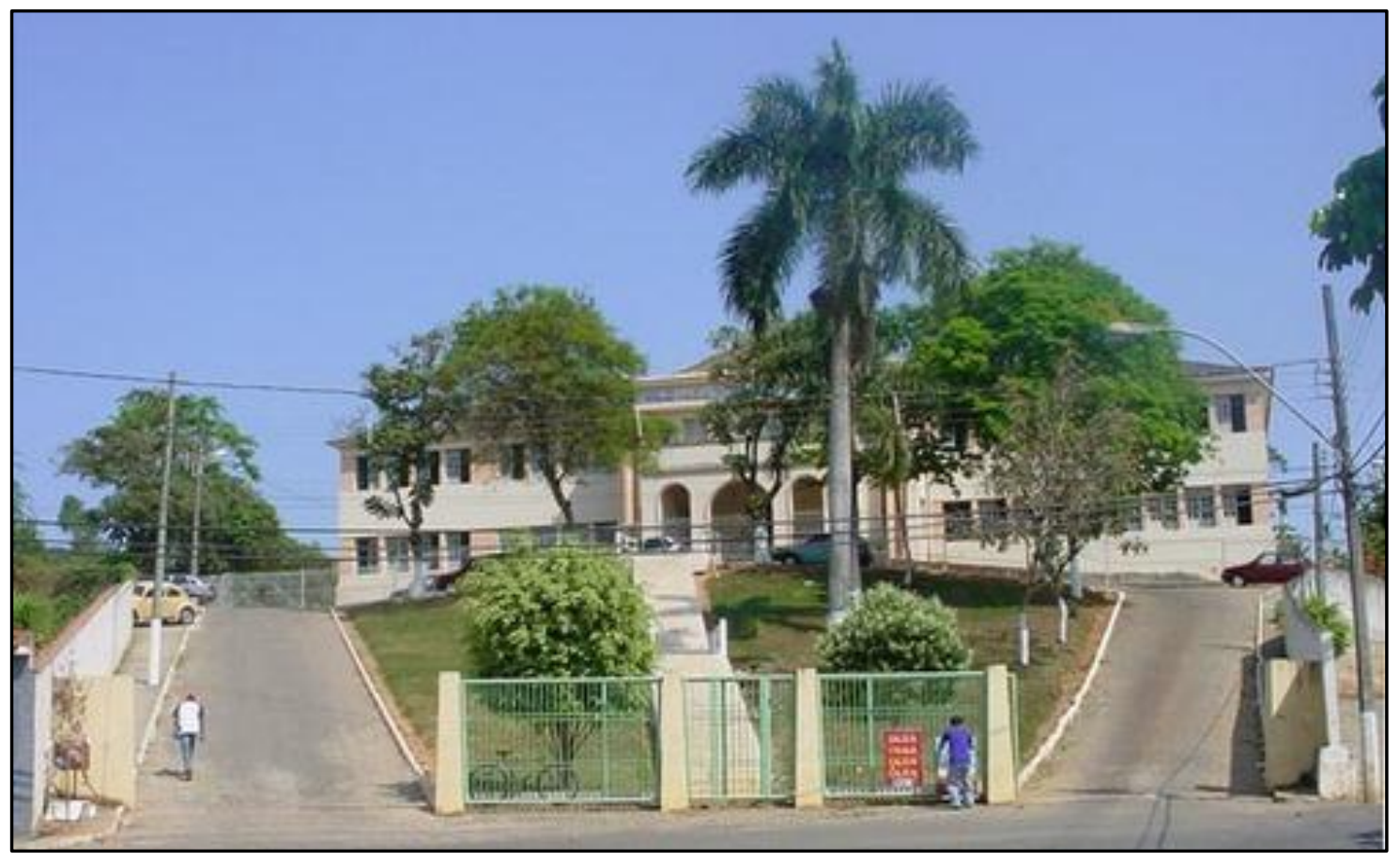

Imagem 1 - Prédio onde funcionava a Escola Normal de Alegre. Fonte: Higor Henrique Lube ${ }^{4}$.

A estrutura das provas podem ser assim descritas: apresentada em papel almaço pautada, trazendo um cabeçalho onde indica escola, local, data, número da prova, número do ponto sorteado e identificação da turma. A identificação do aluno está na parte direta superior, a qual é destacada para que a correção fosse sem identificação do aluno.

Na figura 1 é possível observar a aparência da prova de Sociologia.

\footnotetext{
${ }^{2}$ Busca oficialmente de permissão e reconhecimento legal de similaridade da estrutura pedagógica entre as duas instituições de ensino, o que proporcionava ao Escola Normal Municipal de Alegre maior reconhecimento e credibilidade.

${ }^{3}$ Informação contida do cabeçalho das provas encontradas no Arquivo Público do Estado do Espírito Santo.

${ }^{4}$ Disponível em:< http://www.panoramio.com/photo/5844959> Acesso em: 25 dez. 2015.
} 


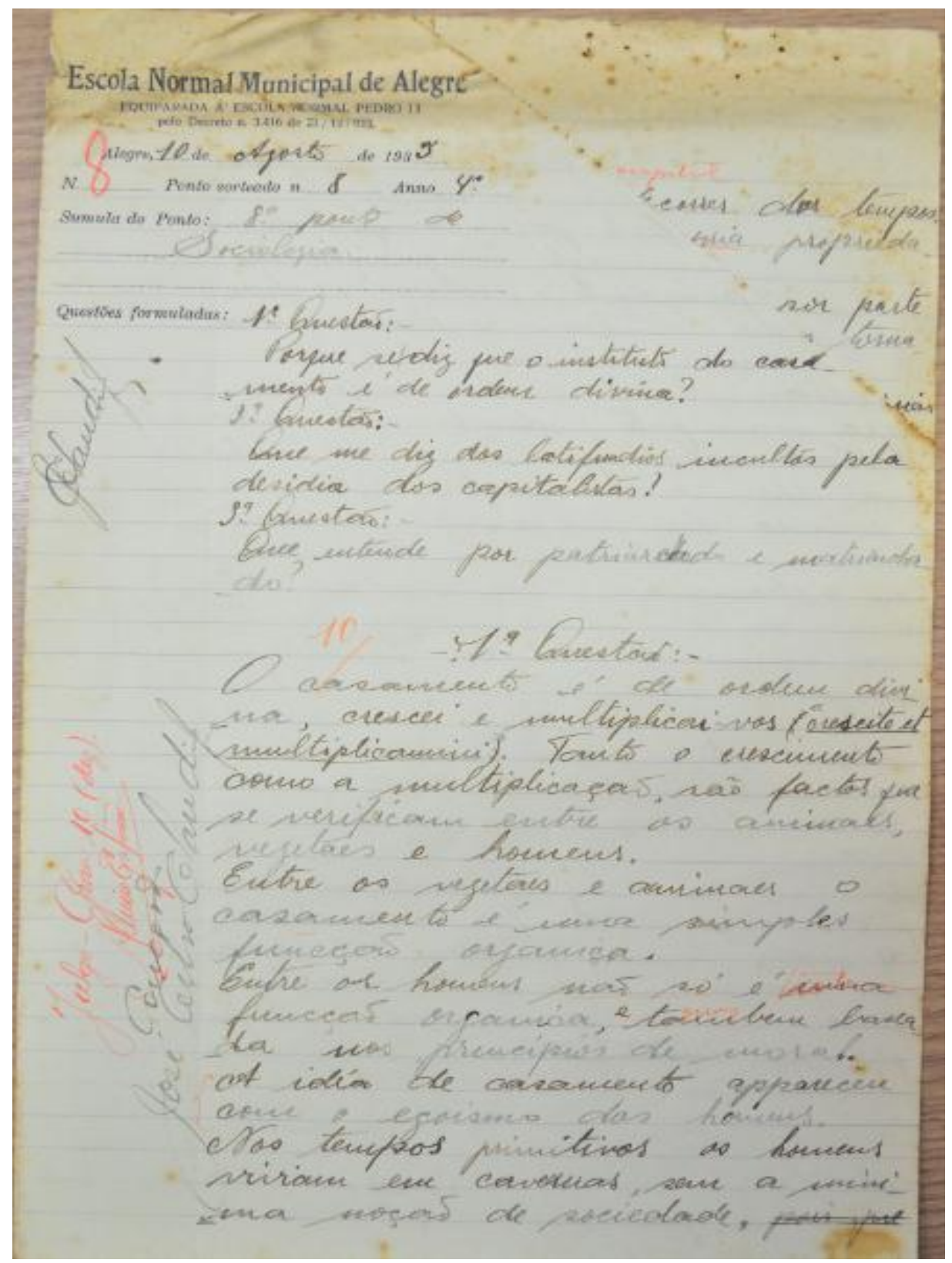

Imagem 1 - Primeira folha de uma das provas de Sociologia aplicadas na Escola Normal Municipal de Alegre, em 10 de agosto de 1935.

Fonte: Arquivo Público do Estado do Espírito Santo.

As provas analisadas trazem três questões discursivas, as quais destacamos no quadro 1.

\begin{tabular}{|c|c|}
\hline $\mathbf{N}^{\mathbf{0}}$ & Questões da Prova \\
\hline 1 & Por que se diz que a instituição do casamento é de ordem divina? \\
\hline 2 & Que me diz dos latifúndios incultos pela desídia dos capitalistas? \\
\hline 3 & O que entende por Patriarchado e Matriarchado? \\
\hline
\end{tabular}

Quadro 1 - Questões da prova aplicada na Escola Normal Municipal de Alegre (1930).

Fonte: elaboração própria a partir das provas analisadas.

Revista Em Debate (UFSC), Florianópolis, volume 13, p. 30-51, 2015. ISSNe 1980-3532 
Em um primeiro momento estaremos observando as questões propostas aos alunos para realizarmos algumas considerações. No segundo momento buscaremos identificar as abordagens dos alunos e, por fim, observar a aferição avaliativo do(a) professor(a) que fez a correção da prova. A proposta é observar nos fragmentos que encontramos de prática cotidiana - materializada em provas escolares - as concepções presentes no ensino de Sociologia em seu menor recorte: na sala de aula.

Por meio da tabela 1 apresentamos as notas aferidas em cada uma das três questões das provas. Os números de identificação das provas foram realizadas pela própria Escola.

Tabela 1 - Notas aferidas a cada uma das três questões da prova de Sociologia aplicada na Escola Normal Municipal de Alegre (10 de agosto de 1935).

\begin{tabular}{cccc}
\hline \multirow{2}{*}{$\begin{array}{c}\text { No de identificação da } \\
\text { Prova }\end{array}$} & \multicolumn{3}{c}{ Notas } \\
\cline { 2 - 4 } & Questão 1 & Questão 2 & Questão 3 \\
\hline $\mathbf{1}$ & 9 & 10 & 10 \\
$\mathbf{2}$ & 9 & 9 & 9 \\
$\mathbf{5}$ & 10 & 9 & 10 \\
$\mathbf{6}$ & 10 & 9 & 10 \\
$\mathbf{7}$ & 6 & 6 & 6 \\
$\mathbf{8}$ & 10 & 9 & 7 \\
$\mathbf{9}$ & 7 & 7 & 10 \\
$\mathbf{1 0}$ & 10 & 9 & 10 \\
$\mathbf{1 1}$ & 10 & 10 & 7 \\
$\mathbf{1 2}$ & 7 & 8 & \\
\hline
\end{tabular}

Fonte: Elaborado pelo autor com base nas provas.

Por meio da tabela 1 notamos a distribuição das notas de cada uma das questões. A nota máximas aferida as três questões foi 10,0. A menor nota das três questões foi 6,0 , todas referente a prova de número 7. Devido aos limites físicos desse artigo vamos nos ater às respostas que julgamos mais emblemáticas.

A primeira observação a ser realizada refere-se à primeira questão, a qual notase a falta de espaço dado ao aluno em responder a questão sem, contudo, se ater a uma explicação religiosa. Não se discute a origem divina do casamento, apenas há espaço para explicar porque dessa origem.

Na segunda questão notamos uma temática bem próxima da realidade dos alunos do município de Alegre: o latifúndio. Tal tema, pelo contexto da época, é marcado pelo confronto ideológico de um país agrário que busca a modernização. 
Comparando as duas questões podemos notar, de certa forma, um conflito entre uma Sociologia Católica e uma Sociologia Cientificista, como Silva (2010), Meucci (2011) e Cigales (2015) indicaram existir nesse período. A primeira questão está marcada por explicações religiosas, enquanto que a segunda parece propor compreender as relações de poder a partir de explicações um pouco mais complexas das formas de produção, embora já definido que a latifúndio seria fruto da "preguiça" dos capitalistas. Em ambas as questões nota-se um posicionamento ideológico definido em torno dos dois temas abordados: casamento e latifúndio.

A terceira questão, em um primeiro momento, nos parece apresentar um tom de neutralidade científica próprio do pensamento positivista que se consolidada no país. Analisaremos posteriormente essa questão com maior rigor.

Para Moraes (2011, p. 367) os discursos que buscavam legitimar o ensino Sociologia até os anos de 1940 "tendia mais para uma concepção conservadora, de controle social, do que de emancipação e crítica". Esse momento da história do ensino de Sociologia foi marcado também por uma forte presença das ideias cristãs (CIGALES, 2014, 2015; MEUCCI, 2011; DAROS; PEREIRA, 2015). Daros e Pereira (2015) buscando analisar a prática de ensino da Sociologia Cristã em uma escola normalista de Santa Catarina destacaram a influência de Alceu Amoroso Lima nas discussões em torno do ensino de Sociologia no Brasil e a tentativa de se opor aos liberais da época. Em pesquisa empírica no Colégio Coração de Jesus, Daros e Pereira (2015) buscaram localizar livros, periódicos e outros impressos relacionados à formação docente e dentre eles encontraram sete obras ligadas a Sociologia e/ou a Educação que traziam ideais católicos. Eram elas as obras de Alceu Amoroso Lima, "Preparação à Sociologia (1931), "Política" (1931), "Debates Pedagógicos" (1931), "Pela Reforma Política" (1932), "Pela Reforma Social" (1932), as obras de Henry de Passage, "Noções de Sociologia" (1932) e de Daycir Menezes, "Princípios de Sociologia" (1934). O conjunto dessas obras buscavam sustentar uma prática de ensino cristã que se apresentava em oposição à "Sociologia Cientificista". Além do mais, o catolicismo estava consideravelmente presente na política brasileira.

\footnotetext{
A presença da Igreja Católica, [...], fez-se com a incorporação de intelectuais católicos em todos os setores políticos e culturais do serviço público. Alceu Amoroso Lima, por exemplo, uma das referências mais eminentes da renovação católica no Brasil, criou, em 1932, o Instituto Católico de Estudos Superiores, e participou, em 1937, da criação da Universidade Santa Úrsula e, em 1941, da fundação da Universidade Católica do Rio de Janeiro. Exerceu também, no período, o cargo de reitor da então Universidade do Rio de
} 
Janeiro (DAROS, PEREIRA, p. 243, p. 2015).

A princípio, observando as duas primeiras questões propostas na prova notamos uma dicotomia. Por um lado, a primeira questão traz uma visão conservadora do casamento, por outro, realiza uma crítica a configuração do uso das terras brasileiras e, consequentemente, uma crítica ao sistema agrário nacional. Meucci (2011) analisando os livros didáticos destacou que havia uma tentativa de impor, por meio do ensino de Sociologia, um padrão de organização social típico do Estado Novo; o que parece estar presente na segunda questão propostas para os alunos dissertarem.

Quanto a primeira pergunta relativa ao casamento, na prova de número 9, o aluno ao responder essa questão, ainda que inicia sua resposta sob a frase "o casamento é de ordem divida. Crescei e multiplicai, disse Jesus", traz alguns elementos que apontam para seu caráter cultural, tendo destacado a existência de outras formas de casamentos para além daquelas consagradas no interior do cristianismo da época. $\mathrm{O}$ alunos relata existências anteriores de modalidades de casamentos, tendo destacado o regime monogâmico ${ }^{5}$, mencionado a poliandria ${ }^{6}$, passando para a poligamia ${ }^{7}$ até aferir que o casamento monogâmico foi fruto de uma determinação do cristianismo e consolidado, em grande parte, pelo Catolicismo. Frente a essa resposta, o aluno obteve uma nova 7,0, de uma escala de 0 a 10 . Esse mesmo aluno terminou a questão com a seguinte frase: "Depois dessas formas todas, o casamento tomou grande parte da sociedade. Este é constituído pela moral, junção orgânica sensibilidade". O(a) professor(a) complementou: "e que se constitui também questão preciosa para a moral".

Transcrevo uma resposta que obteve a nota máxima, 10,0:

\begin{abstract}
Diz-se que o Instituto do Casamento é de ordem divina, primeiramente porque vimos no próprio Evangelho estas palavras: "Crescite et mutiplicamini" - crescei e multiplicai.

$\mathrm{O}$ ato transmissor da vida no animais irracionais e vegetais não passa de simples função orgânica, no homens além disso, é também acrescida as forças da sacralidade. O Instituto do casamento não é um contrato, como querem muitos, mas sim um sacramento; portanto é de ordem divina. O casamento é uma instituição [que] depois de realizado não pode ser desfeito, ao passo que o contrato pode ser desfeito desde que os contratantes desejam (PROVA 6, QUESTÃO 1, o grifo é intervenção do(a) professor(a)).
\end{abstract}

Nota-se que o embasamento da resposta encontra-se nos preceitos cristãos, em especial no sacramento católico, distanciando-se de uma Sociologia cientificista.

\footnotetext{
${ }^{5}$ Estado de uma pessoa casada apenas com outra uma outra pessoa.

${ }^{6}$ Estado de uma mulher casada simultaneamente com vários homens (é uma das variáveis da poligamia).

${ }^{7}$ Estado de uma pessoa casada ao mesmo tempo com várias outras.
} 
Outro aluno recorreu a uma explicação "evolutiva", destacando a poligamia como um estágio para a monarquia, assim como a poliandria como um estágio anterior à poliginia $^{8}$. Nota-se nesta resposta a presença de uma concepção dominadora do sexo masculino. O aluno escreveu:

Outros sociólogos com maiores razões acham que o homem sim, por seus espíritos retos, sendo mais [forte e mais] social deveria dominar todo este mundo. Era esse regime denominado poliarquia. [...] Afinal, hoje é adotado o regime da monogamia como quer, digo [como] manda a Igreja, e sem o divórcio (PROVA 2, QUESTÃO 1, os grifos são intervenções do(a) professor(a)).

Observa-se na inclusão da nota do(a) professor(a) a necessidade do aluno compreender que a mulher é mais fraca do que o homem. Nessa resposta o aluno obteve a nota 9,0 .

A menor nota aferia a questão 1 , das dez provas que tivemos acesso, foi 6,0 . Nessa prova o aluno respondeu:

\begin{abstract}
É de ordem de divina o casamento, crescei e multiplicai, [assim] disse Jesus. Nos vegetais notamos este fenômeno de crescimento e multiplicação que não são mais que uma simples função orgânica. Este fenômeno é também observado entre os homens não só como uma função orgânica [mas] e tem também [apresentam] uma função de moral.

O casamento veio logo que apareceu no homem os primeiros traços de egoísta.

Os homens primitivos eram nômades e [não] sabiam o que fosse sociedade. Atrasados como eram, achavam que uma só mulher podia pertencer a mais de um homem, tendo então a poligamia. [Uns e outros buscaram diferentemente - origens nas primeiros uniões - uma pessoa].

Mais tarde, como eram chefes incontestados achavam que um homem poderia adquirir quantas mulheres quanto lhe fosse possível [pudesse sustentar], é este o período da poligamia. [...] Mais tarde, já bem depois dos dois períodos, devido ao posicionamento do egoísmo nos homens e os princípios da sociedade [e] graças a compreensão da religião começaram então a viverem os casais, [tendo] uma mulher para cada homem, veio então o período da monogamia. Por motivo da influência do cristianismo passamos a dizer que o casamento é de ordem divina (sic) (PROVA 7, QUESTÃO 1, os grifos são intervenções do(a) professor(a)).
\end{abstract}

$\mathrm{Na}$ resposta do aluno há um posicionamento crítico à submissão da mulher, sendo atribuído sua dominação ao egoísmo do homem. Observamos ainda uma explicação de que a concepção divina do casamento é uma produção cultural da religião cristã. Possivelmente tais apontamentos foram os motivos pela menor nota aferida à questão dentre todas as outras notas atribuídas pelo(a) professor(a). Notamos em todas as questões uma definição conceitual equivocada, o que evidencia que o(a) professor(a)

\footnotetext{
${ }^{8}$ Estado de um homem casada simultaneamente com várias mulheres (é uma das variáveis da poligamia).
} 
não possuía o conhecimento dos conceitos de "poligamia" e "poliginia", confundindoos ou compreendendo poligamia como se fosse sinônimo de poliginia. Tal equívoco pode ser resultado de uma não formação do professor na área, típico desse período.

Em outra prova onde a questão 1 obteve a nota máxima $(10,0)$, notamos que o aluno inicia afirmando ser o casamento uma ordenança divina e pautada nas Sagradas Escrituras (livro Sagrado Cristão). Este trouxe a problematização do casamento como contrato ou como sacramento, defendendo a segunda opção. Assim escreveu o aluno:

\begin{abstract}
Uma pergunta que nos depara a todo momento: o casamento é sacramento ou contrato?

O casamento é sacramento pelos seguintes motivos: $1^{\circ}$ ) $\mathrm{O}$ casamento abrange toda a personalidade dos contraentes e o contrato abrange apenas o ato e nada tem com a individualidade [personalidade] dos contraentes.

$2^{\circ}$ ) o casamento gera relações de direito de carater perfeito e indissolúvel, o contrato rega relações de direito de carater acidental e transitório e dissolúvel. $3^{\circ}$ ) o casamento gera direitos e obrigações de natureza necessária, prescrito pela lei (o contrato gera a) e não podem ser modificados pelos contratantes, o contrato gera direitos e obrigações de natureza acidental, que podem ser modificados mediante um acordo e livremente convencionado, e não são prescrito pela lei.

$4^{\circ}$ ) o casamento determina relações judiciais que não podem ser apreciados materialmente; o contrato determina relações de direito de natureza econômica que podem ser apreciados monetariamente.

$\mathrm{O}$ unico ponto de contato que aproxima o casamento do contrato e que reforça a opinião dos que o consideram contrato, é o (concurle) concurso de duas vontades que entram num acordo, de[les] aceitar[em] [em pertencimento] por marido e por mulher. Isto porém não é o suficiente para identifica-los quando ha diferenças múltiplas e substanciais que os separam. Portanto concluímos, que o casamento é (sace) sacramento e não contrato (sic) (PROVA 11, QUESTÃO 1, os grifos são intervenções do(a) professor(a)).
\end{abstract}

Observando as respostas dadas a questão de número 1 da prova (Por que se diz que a instituição do casamento é de ordem divina?) tidas como correta pelo(a) professor(a), notamos a presença de uma explicação religiosa para o fenômeno social "casamento". Não é possível afirmar que trata-se de uma influência da Sociologia Cristã (já bastante presente na Franca e nos Estados Unidos) ou reflexo da cultura religiosa na prática de ensino de Sociologia. Contudo, é sabido que, na época, configurava-se um cenário nacional marcado por disputas político-ideológicas que dividia, inclusive, a Associação Brasileira de Educação - $\mathrm{ABE}^{9}$, destacando-se nessa disputa intelectuais liberais e católicos. A concepção de uma escola laica, defendida pelos liberais, ganhou destaque após a publicação do Manifesto Pioneiro da Educação Nova, em 1932

\footnotetext{
${ }^{9}$ Instituição da sociedade civil de adesão voluntária, fundada em 16 de outubro de 1924, no Rio de Janeiro, com o objetivo de discutir os rumos da educação brasileira.
}

Revista Em Debate (UFSC), Florianópolis, volume 13, p. 30-51, 2015. ISSNe 1980-3532 
(CIGALES, 2015). Os fragmentos aqui analisados evidenciam que tal princípio de laicidade ainda não havia interiorizado no país em 1935, pelo menos não na Escola Normal Municipal de Alegre.

A questão 2 da prova traz, como demonstrado no quadro 1, a seguinte pergunta: Que me diz dos latifúndios incultos pela desídia dos capitalistas? Tal questão suscita uma temática central nos debates do Estado Novo: a modernização brasileira.

As provas de número 01 e 11 foram as únicas que obtiveram nota máxima $(10,0)$ na questão 2. Transcreveremos trechos dessas duas provas que diferenciam-se substancialmente das demais, podendo ser o motivo de sua nota.

$\mathrm{Na}$ prova de número 01 o aluno inicia sua resposta apresentando a origem etimológica da palavra latifúndio e suas origens ainda antes de Cristo para, em seguida, aferir o seguinte julgamento:

[...] e foi causa de tamanhos e dissidios e convulções sociais. A história triste dos Gregos fala-nos da cruel consequência do latifúndio que trouxe a vida cível, a ruina, desmantelo e a morte. Foi talvez a cruel experiência dos fatos que levou Plinio a exclamar "Latifundea perdidare Italiane". Os consequências do latifúndio foram cruéis, não só na Europa, mas em todo o mundo. A terra, o ar, a luz, não é de ninguém, mas de todos. A terra portanto devia ser de todos, foi o homem que egoisticamente a dominou. Embora a propriedade de terra seja legitima ela so sera justa, se tiver por base a utilidade social. Principalmente concebida debaixo das concepções Christans, como diz o papa Leão XIII na sua Enciclica "Rerum Novarum". "A propriedade da terra só será justa se justa se tiver por base a utilidade social". A esse respeito diz o economista Gide "Uma vez que a propriedade de terra tem por base a utilidade social ela será justa, mas o agricultor que deixar de tirar dessas propriedade (que ela) a utilidade que ela comporta, não terá direito de exercer esta função.

Gide; acha que em vez de grandes extenções de terras doadas por um so capitalista, devia existir pequenas propriedades pertencentes cada uma a um dono.

Com o fim de melhorar o inconveniente da propriedade agraria, surgiu em Roma o "Instituto Juridico Enfiteuse" . Em nosso Espírito Santo ja se compreendeu-se este fenômeno de maneira elevada, com a lei $\mathrm{n}^{\circ} 1148$ de 2112-917. Diz esta lei que as terras do território podem ser vendidos em extensas áreas para cada família de agricultor nacional ou extrangeiro, estas áreas são de 60 hectares.

No Brasil o fenômeno do latifúndio se processou da seguinte maneira: ha imensos tratos de terras, verdadeira expressão latifundiárias foram doadas para uns em detrimento de todos. (?)

O latifúndio é um fenomeno que deve ser combatido. Os Capitalistas que possuem imensos tratos de terra e não cultivam, deixando portanto de ter uma utilidade coletiva, não têm o direito de exercer esta função. (sic) (PROVA 1, QUESTÃO 2, os grifos são intervenções do(a) professor(a)).

Nota-se que existe na resposta, considerada pelo professor como exemplar, duas bases que a fundamenta: o argumento baseada na autoridade religiosa (usado primeiro) e na autoridade intelectual; esta apenas para fortalecer ou legitimar o primeiro 
argumento.

Observando a questão 2 da prova 11, que também obteve a nota máxima, notamos uma grande semelhança nos elementos contidos na resposta, assim como sua estruturação argumentativa, o que pode evidenciar que existia um discurso docente que precisava ser reproduzido pelo aluno; este marcado pela forte influência da ideologia católica da época. A estrutura das respostas é basicamente a mesma, iniciando com a origem etimológica da palavra latifúndio, passando pela sua origem, destacando as convulsões sociais que esta gera, mencionando a frase de Plinio, destacando a Encíclica Papal e, posteriormente, apresentando o argumento do economista Charles Gide ${ }^{10}$.

Buscamos observar a prova de número 7 , que recebeu na questão de número 2 , a menor nota $(6,0)$ :

\footnotetext{
Que me diz dos Latifundios incultos pela dissidia dos capitalistas?

Latifundio vem do latim - Lates = largos - fundie = capitaisl, que significa grandes capitaisl. No decorrer dos tempos com a evolução da etmologia da palavra foi invertido seu sentido de propriedade.

Como eram grandes os proprietários, os proprietários começaram a deixa-las incultas. Em Roma como eram colossais e acarretavam grandes prejuízos, levou Plinio o Moço velho a exclamar "Latifundia Ferdiere Italiam", os latifúndios perderam a Italia. Muitos anos depois é baixado um decreto pelo governo que desapropriava os grandes latifúndios e dividiu-os em pequenas partes que eram entregues a pequenos proprietários, e com essa decisão do governo Roma é progredidau.

Gide diz que a propriedade é justa desde que tenha utilidade social.

Aqui no Brasil ainda encontramos grandes extenȩsões de terras incultas que foram adquiridas por meio do dinheiro, herança etc.

No Espírito Santo tem uma lei que põe a 60 hectares de terra a disposição de qualquer família coloniais, podendo ser brasileiro ou extrangeirio (sic) (PROVA 7, QUESTÃO 2, os grifos são intervenções do(a) professor(a)).
}

A diferença mais significativa entre a prova de número 1 e 11 , que obtiveram nota 10,0 na questão de número 2, para a resposta da prova de número 7 está na ausência do embasamento da autoridade religiosa.

Por fim, passamos a observar a questão 3, que a princípio nos pareceu ser a mais próxima de uma Sociologia cientificista. Tal questão foi assim colocada pela escola: "O que entende por Patriarchado e Matriarchado?" Notamos que o desempenho dos alunos nessa questão mostrou-se melhor em relação as demais. Seis (6) alunos obtiveram nela a nota máxima. A menor nota foi aferida a prova de número 7, sendo 6,0 pontos.

Na prova de número 6, encontramos uma das respostas tida pelo(a) professor(a) como exemplar. Assim respondeu o aluno:

${ }^{10}$ Possivelmente era utilizado a obra "Princípios da Economia Política" traduzido pelo sociólogo, Historiador e militante do Partido Federalista Félix Contreiras Rodrigues, pela editora Globo (192?). A terceira edição é datada de 1931.

Revista Em Debate (UFSC), Florianópolis, volume 13, p. 30-51, 2015. ISSNe 1980-3532 
Por patriachado entende-se logicamente uma consequencia da poligamia. Poligamia é quando o homem dando expansões ao seus instintos bestiais e sua sensualidade consegue dominar e adquirir quantas mulheres desejar, vindos dali a ideia de Patriarcado que quer dizer a autoridade que os pais têm sobre os filhos.

Por Matriarcado entende-se logicamente a consequência da poliandria.

Poliandria é quando a mulher é que consegue dominar muitos homens.

Da poliandria é que vem a ideia de Matriarchado que é a autoridade da mãe sobre os filhos.

Hoje os filhos tem mais soma de direitos que de deveres para com os pais. (sic) (PROVA 6, QUESTÃO 3, os grifos são intervenções do(a) professor(a)).

Outra prova que obteve a nota 10 foi a de número 11 . Nessa prova encontramos a seguinte resposta:

Entende-se por matriarcado, o fenômeno que se observou nos tempos mais remotos da antiguidade, em que a mulher possuía muitos maridos, isto é, no regimem da poliandria. aA prole densamparada de outro arrimo e proteção, ficava (so) submissa exclusivamente à mulher.

O patriarcado originou-se, no "Instituto-do Patrio Poder em que o homem por ser mais forte, mais sensual, mais egoísta a possuía tantas mulheres quantas lhe fosse possível dominar ou conquistar.

Chefe incontestado do núcleo familiar tinha filhos na mais dura (subimicio) submissão.

Atualmente adota-se a monogamia (sic) (PROVA 11, QUESTÃO 3, os grifos são intervenções do(a) professor(a)).

Nossa hipótese inicial de que a questão 3 parecia ser a menos "carregada de ideologia religiosa" parece se confirmar, ainda que nota-se uma visão de época marcada pela dominação masculina, o que é presente tanto no seio da Igreja católica, quanto na ciência da época.

Observando as provas que obtiveram notas menores não notamos elementos ideológicos ou cientificista que justificam as notas, apenas uma escrita menos cuidadosa, ainda que nota-se a presença dos mesmos apontamentos das demais provas, como se observa na imagem 2 referente a resposta da questão 3 da prova 12: 


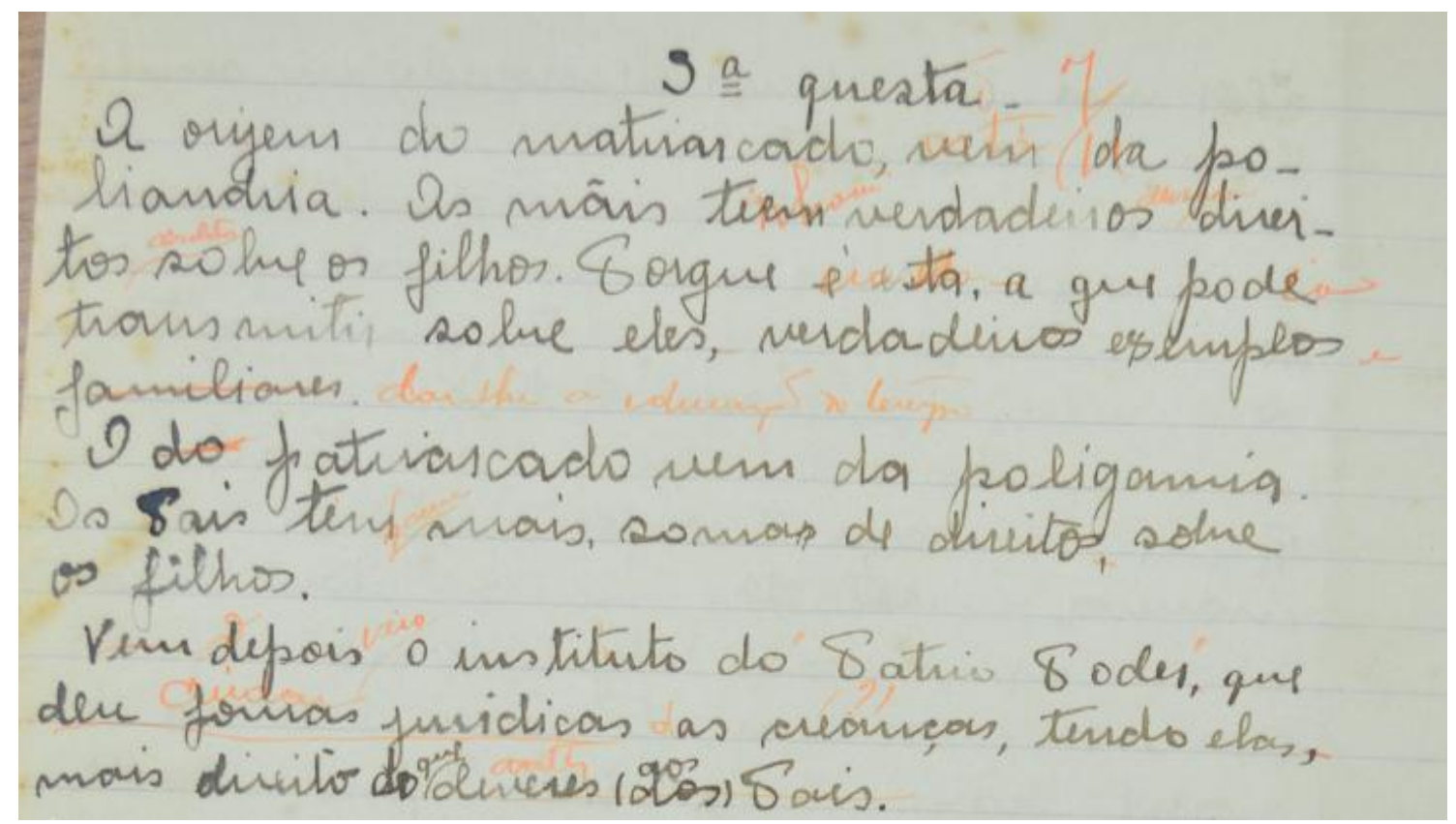

Imagem 2 - Resposta da questão 3 da prova (número 12) de Sociologia aplicada na Escola Normal de Alegre, em 10 de agosto de 1935.

Fonte: Arquivo Público do Estado do Espírito Santo.

Os fragmentos do ensino de Sociologia analisados nesse artigo nos possibilitam aferir algumas considerações. Há uma forte influência de uma ideologia católica que nos parecer ter sido absorvida pelos alunos de forma não reflexiva, dada as semelhanças das dissertações dos alunos. As respostas dadas pelos alunos parece buscar repetir o que foi lecionado em sala de aula, prática comum na pedagogia tradicional.

Não é possível afirmar que nesse período tenhamos uma "Sociologia Católica", como aquela evidenciada por Cigales (2015), aferição que só seria possível se tivéssemos acesso aos manuais utilizados pelo(a) professor(a). Ainda que em 1935 já tínhamos, no mínimo, sete obras limitantes de uma Sociologia Cristã, os seus autores não são mencionados nas dissertações dos alunos e como as respostas dadas nas provas são muito semelhantes nos leva a crer que não eram mencionados pelo(a) professor(a) em sala de aula, tendo optando por citar o economista Charles Gide. O que temos é uma Sociologia pré-acadêmica. Embora em 1935 já contávamos com três cursos superiores em Ciências Sociais (um na Escola Livre de Sociologia e Política de São Paulo, um na Universidade de São Paulo e um Universidade do Distrito Federal) a ênfase na formação não estava na docência, antes focado na "formação de quadros para a burocracia estatal e privada ou formação de pesquisadores, sempre amesquinhando a formação de professores" (MOARAES, 2011, p. 363). Só em 1939, por meio do Decreto-Lei n. 1.190, de 4 de abril de 1939 (art. 49) que é criado na Universidade de 
São Paulo o curso Didático, sendo conferido o diploma de licenciado ao bacharel que o cursar, o que se dava em mais um ano de estudos. Todos essas informações fortalece a hipótese de que as provas aplicadas na Escola Normal Municipal de Alegre em 1935 eram elaboradas por professores não formados em Ciências Sociais/Sociologia. Não é possível, como já mencionado, afirmar que tratava-se de uma Sociologia Católica, acreditamos ser mais prudente afirmar que tínhamos na Escola Normal Municipal de Alegre o ensino de uma "Sociologia pré-científica", com forte influência religiosa/católica.

Chamamos de "Sociologia pré-científica" aquela marcada por prenúncios de uma cientificidade, porém ainda impregnada de explicações sem rigor científico, sobretudo presa, em certa medida, a religiosidade e a moral de uma época; o que nos parece caracterizar bem os fragmentos de ensino de Sociologia aqui analisados. Diferentemente de uma "Sociologia Católica", marcada por um corpo teórico e um esforço político-ideológico claro, parece que os fragmentos de ensino analisados nos apontam para uma "Sociologia pré-científica" marcada pelo históricos ensinamentos católicos presentes na educação brasileira da época.

Nosso argumento de que é possível identificar nas provas uma "Sociologia précientífica" baseia-se no fato de que os fragmentos analisados indicam haver uma importância maior dadas as explicações de cunho religioso, sendo presente o uso da autoridade religiosa para validação dos argumentos; além de uma presença marcante da ideia de moral cristã, católica. Ainda que em alguns momentos a explicação de cunho histórico tenha sido mobilizada pelos alunos, nos parece que o(a) professor(a) considerou mais importante os elementos da moralidade católica, o que nos permitem afirmar que estamos diante de um ensino de uma "Sociologia pré-cientificista".

Talvez a importância dada a moral possa ser explicada pela concepção conservadora da Sociologia destacada por Moraes (2011) ou/e pela sua origem no Brasil, quando em 1890, Benjamim Constant, então Ministro da Guerra, introduziu o ensino de "Sociologia e Moral" nas escolas do Exército e a propôs, ainda que sem êxito, que na Educação Básica constaria essa disciplina.

\section{CONSIDERAÇÕES FINAIS}


Não é possível encontrar, até 1933, espaços oficiais de formação e produção acadêmica na área de Sociologia e por isso convencionou-se denominar esse período de fase pré-acadêmica. Portanto, o ensino de Sociologia, nos cursos de preparação para o exercício do magistério, nas escolas normais, e nas então denominadas Escolas Secundárias era ministrado por professores sem formação específica (SILVA, 2010, p. 16), o que talvez "justificasse" um equívoco conceitual básico presente em todas as provas analisadas. Embora Meucci (2011) tenha destacado que a partir da inclusão obrigatória da Sociologia no ensino secundário em 1925, e ratificada em 1930, a Sociologia tivesse sido vista “[...] como uma área de conhecimento dedicada à renovação da vida intelectual, à substituição do ensaísmo jurídico e literário pelo realismo científico" (MEUCCI, 2011, p. 57), ao observar as provas aplicadas na Escola Normal Municipal de Alegre em 10 de agosto de 1935 encontramos o que parece ser uma Sociologia não só "pré-acadêmica", como também "pré-científica". "Os fragmentos de ensino de Sociologia" que analisamos nos indicam que na referida escola havia um ensino de Sociologia marcada pela moralidade da época e por explicações religiosas dos fenômenos sociais, explicações que eram transmitidos aos alunos e desejáveis que esses as absorvessem de forma acrítica. A autoridade religiosa possuía uma centralidade das argumentações em torno de temas de ordem "moral" e em acordo com o posicionamento ideológico da Igreja Católica, ainda que notamos a presença do uso da autoridade acadêmica para reforçar tais argumentos explicativos da realidade social. Certamente o fato de tratar-se de uma escola interiorana localizada numa sociedade católica, a Sociologia Cientificista que se desenvolveu no Brasil nesse período teve maiores dificuldades de se consolidar.

Ainda que tenhamos diversas obras que buscavam propagar uma Sociologia Católica ou Cristã e uma forte influência desta na Associação Brasileira de Educação (ABE) entre 1929 a 1932, não encontramos nas provas referências diretas às obras publicadas por Alceu Amoroso Lima (ou com seu pseudônimo Tristão de Athayde), Djacir de Meneses e Henry du Passage, ou outro representante da Sociologia Cristã.

É certo que nesse paper temos apenas fragmentos de 1935 do ensino de Sociologia em uma escola normalista e que não nos possibilita compreender todo o contexto, mas nos apresenta elementos para conhecermos um pouco mais a ainda fragmentada história do ensino de Sociologia. 


\section{Referências}

AZEVEDO, Fernando de. Princípios de Sociologia: pequena introdução ao estudo de sociologia geral. 11 a edição. São Paulo: Duas Cidades, 1973.

CIGALES, Marcelo Pinheiro. O Ensino da Sociologia no Brasil: Perspectiva de análise a partir da História das Disciplinas Escolares. Revista Café com Sociologia. vol.3, nº1. Jan. de 2014. Disponível em: < http://revistacafecomsociologia.com/revista/index.php/revista/article/view/100> . Acesso em: dez. 2015.

Raymond Murray e a Sociologia Católica no Brasil: notas sobre um manual da década de 1940. Revista Café com Sociologia. Vol.4, no 3 , dez. 2015. Disponível em: <

http://revistacafecomsociologia.com/revista/index.php/revista/article/view/595> . Acesso em: dez. 2015.

DAROS, Maria das Dores; PEREIRA, Elaine Aparecida Teixeira. A sociologia cristã e o pensamento de Alceu Amoroso Lima em um colégio católico de formação de professoras em Santa Catarina. Revista Brasileira de História da Educação, MaringáPR, v. 15, n. 1 (37), p. 235-267, jan./abr. 2015. Disponível em: < http://www.rbhe.sbhe.org.br/index.php/rbhe/article/view/634>. Acesso em: dez. 2015.

DIÁRIO DA MANHÃ. Pedido da Escola Normal Municipal de Alegre de equiparação oficial ao Colégio Pedro II. 12 de nov. 1933.

DIÁRIO DA MANHÃ. Formatura da turma normalista da Escola Normal Municipal de Alegre. 20 de novembro de 1933.

FERNANDES, Florestan. A sociologia no Brasil: contribuições para o estudo de sua formação e desenvolvimento. $2^{a}$ edição. Petrópolis: Vozes, 1980.

LIEDKE FILHO, Enno D. A Sociologia no Brasil: história, teorias e desafios. Sociologias, Porto Alegre, ano 7, nº 14, jul/dez, p. 376-437, 2005. Disponível em:< http://www.scielo.br/pdf/soc/n14/a14n14>. Acesso em: dez. 2015.

MEUCCI, Simone. A institucionalização da sociologia no Brasil: primeiros manuais e cursos. Dissertação de mestrado. Campinas, UNICAMP, (março) 2000.

Institucionalização da sociologia no Brasil: primeiros manuais e

cursos. São Paulo: Hucitec: Fapesp, 2011.

MORAES, Amaury. Ensino de Sociologia: periodização e campanha pela obrigatoriedade. Cadernos Cedes, Campinas, vol. 31, n. 85, p. 359-382, set.-dez. 2011. Disponível em: < http://www.scielo.br/pdf/ccedes/v31n85/04v31n85.pdf > Acesso em: dez. 2015.

OLIVEIRA, Amurabi. Revisitando a história do ensino de Sociologia na Educação Básica. Acta Scientiarum. Education. Maringá, v. 35, n. 2, p. 179-189, jul-dez., 2013. 
Disponível: < http://www.redalyc.org/pdf/3033/303328749005.pdf $>$. Acesso em: dez. 2015.

SILVA, Ileizi Luciana Fiorelli. O Ensino das Ciências Sociais/Sociologia no Brasil: histórico e perspectivas. In: MORAES, Amaury César (org.). Sociologia: ensino médio. Coleção Explorando o Ensino, v. 15. Brasília: Ministério da Educação, Secretaria de Educação Básica, 2010. 